\title{
QUALITATIVE STUDIES ON THE AMINO ACID COMPOSITION OF UREASE
}

\author{
KIYOMICHI HANABUSA \\ Department of Biochemistry, School of Medicine \\ Keio University, Tolyo
}

(Received for publication January 27, 1962)

Only a little information is available on the amino acid composition of jack bean urease at present. Panek has shown by paper chromatography that urease contains 14 kinds of amino acid(1) and, in addition to them, 4 amino acids have been added recently(2).

The present experiments were undertaken to confirm the presence of these amino acids in crystalline urease prepared from jack bean cultured in Japan.

\section{EXPERIMENTALS}

Enzyme:-Crystalline urease used was prepared as reported previously $(3,4)$ and recrystallized three times according to the method of Dounce(5).

Preparation of hydrolysate:-The hydrolysis of urease for the paper chromatographic determination was carried out with hydrochloric acid and barium hydroxide by a slight modification of the procedure of Block(6). Both the hydrolysates were finally dissolved in $10 \%$ isopropyl alcohol so as to contain the equivalent of $40 \mathrm{mg}$ of urease per millilitre. The acid hydrolysate solution was further diluted when necessary. An $0.005 \mathrm{ml}$ aliquot of these solutions was spotted on a filter paper.

Paper chromatography:--The separation of each amino acid in the hydrolysate was effected by paper chromatography. For this purpose, sheets $(40 \times 40 \mathrm{~cm})$ of Whatman No. 1 filter paper were used and chromatograms were obtained by two-dimensional ascending technique. Following solvents were employed for developing.

First run:-80\% phenol containing $0.5 \%$ ammonia and $0.04 \%$ 8-hydroxyquinoline. Developed for 24 hours.

Second run:-Butanol:acetic acid:water $(4: 1: 2 \mathrm{v} / \mathrm{v})$ was used. Developed for 17 hours.

The separated amino acids on the chromatogram were detected by spraying 
$0.5 \%$ Butanol solution of ninhydrin and heating at a constant temperature of $70^{\circ} \mathrm{C}$ for 30 minutes.

\section{RESULTS AND DISCUSSION}

The colour reactions widely used in the detection of amino acid components in protein were tried on the solution of this enzyme directly and they all gave positive signs. It was ascertained from these results that it contains cysteine (or cystine, from evidence of sulfide ion liberated by alkali), tryptophan (Hopkins-Cole reaction), tyrosine (Millon reaction), and arginine (Sakaguchi reaction).

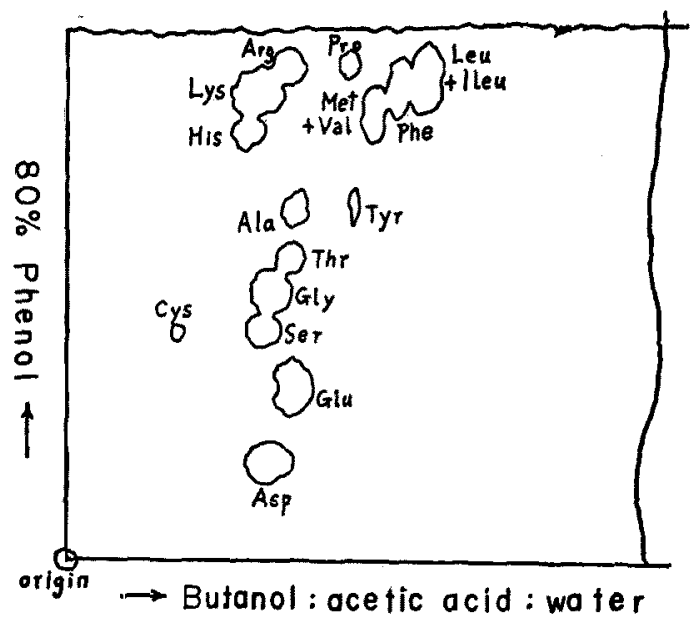

Fig. 1 Paper chromatogram of acid hydrolysate of urease (equivalent of $200 \mu \mathrm{g}$ of urease was spotted).

The chromatogram of the acid hydrolysate is shown in Fig. 1, on which 15 spots of amino acid can be recognized. They were identified with cystine, aspartic acid, glutamic acid, serine, glycine, threonine, alanine, tyrosine, arginine, lysine, histidine, proline, phenylalanine, methionine + valine, and leucine + isoleucine. Identification of each amino acid was made by comparing with the chromatogram obtained with standard solution of pure amino acids. The cystine spot was the most faint among them and as the mixed spots such as methionine + valine and leucine+isoleucine could not be separated satisfactorily under the conditions used, absence of either members in these spots might be possible.

Further experiments were tried to make a rough estimate of the content of these amino acids in the urease molecule. The same amount of acid hydrolysate solution, which had been gradiently diluted, and a standard solution of amino acids in varied concentrations were submitted to paper chromatography. The 
minimum concentration required for detection and the size of spots were compared with those of the standard solution. From the results of these experiments, it was presumed that cystine is present in the smallest quantity and glutamic acid, aspartic acid and leucine + isoleucine are in a relatively large amount. These values are considered to correspond approximately to 100 residues of cystine and 400-500 residues of amino acids present in a relatively large amount, on the basis of a molecular weight of urease calculated as 483,000 (7).

The tryptophan spot which was expected on the chromatogram of alkaline hydrolysate could not be demonstrated. This is probably due to the fact that its spot could scarecely be separated from other spots or its content in the enzyme is too small to be detected.

The presence of carbohydrate and phosphorus was also examined, but neither of these components was detected.

\section{SUMMARY}

1. The amino acids composing urease were identified by paper chromatography and colour reactions of protein. It was found that urease contains, at least, 16 amino acids.

2. Among the amino acids found in urease, it was presumed that cystine is present in the smallest quantity and glutamic acid, aspartic acid, and leucine+ isoleucine are in a relatively large amount.

3. The presence of carbohydrate and phosphorus in this enzyme was not demonstrated.

\section{REFERENCES}

1. Panek, A. D.: Chem. Abstr., 50: 14054, 1956.

2. Varner, J. E.: “The Enzymes", 2nd ed., Vol. 4, 256, Academic Press Inc., New York, 1960.

3. Hanabusa, K.: High-yield erystallization of urease from jack bean. Nature, 189; $551,1961$.

4. Hanabusa, K.: Preparation of urease crystal from jack bean. Nature, 193: 1078, 1962.

5. Dounce, A. L.: An improved method for recrystallizing urease. J. Biol. Chem., 140: 307, 1941.

6. Block, R. J.: Estimation of amino acids and amines on paper chromatograms. Anal. Chem., 22: 1327, 1950.

7. Sumner, J. B., Gralén, N. and Eriksson-Quensel, I. B.: The molecular weight of urease. J. Biol. Chem., 125: 37, 1938. 